\title{
Literatura: um estudo de caso da leitura dos clássicos brasileiros no Ensino Médio
}

\author{
Literature: a case study of the reading of brazilian classical novels in \\ high school
}

\section{Eliza da Silva Martins Peron}

Universidade Federal de Mato Grosso do Sul - UFMS - Três Lagoas - Mato Grosso do Sul - Brasil

\section{Emilio Davi Sampaio}

Universidade Estadual de Mato Grosso do Sul - UEMS - Dourados - Mato Grosso do Sul - Brasil

Resumo: Este artigo apresenta o resultado de uma pesquisa realizada em duas escolas localizadas no município de Dourados - MS sobre a leitura dos romances clássicos. Com o objetivo de preservarmos a identidade das instituições, denominamos as escolas como $\mathrm{A}$ e $\mathrm{B}$, sendo que a escola $\mathrm{A}$ pertence à rede pública de ensino e a escola $B$ à rede privada. Como método de investigação, aplicamos questionários com questões fechadas e abertas aos alunos do terceiro ano do ensino médio. Este material nos permitiu uma abordagem da situação atual da leitura dos romances clássicos. A partir desses dados e, pautados em alguns estudiosos do tema, foi possível descrever a realidade de forma ampla a fim de evidenciar o que esses jovens leitores, estudantes do ensino médio, têm a nos dizer, sobre suas leituras ou não leituras dos romances clássicos brasileiros.

Palavras-chave: Leitura. Literatura. Clássicos brasileiros. Estudo de caso.

Abstract: This article shows the result of a research realized in two schools in the city of Dourados - MS about the reading of classical romances. We called the schools like $A$ and $B$ with the purpose of preserve the identity of these institutions, being that the $A$ school belongs to the public network and the $B$ school belongs to private one. We applied questionnaires with closed and opened questions for the students of the third year of High School as research method. This material allowed an approach of the currently situation of the reading of classical novels. Thus, it was possible describe the reality broadly in order to highlight what these young readers, students of the High School, have to say us about their readings or non-readings of Brazilian classical romances from these data and based in some scholars of the theme.

Keywords: Reading. Literature. Brazilian classical novels. Case study. 


\section{Introdução}

A leitura é um ato solitário e faz com que se estabeleça uma íntima relação entre dois corpos: quem lê (o ser humano) e o livro (a mensagem) o qual se está lendo. A humanidade só conhece a sua história, seus mais eruditos e triviais motivos, porque possui livros. Neles permanecem assentadas as mais variadas formas de expressão, desde as sentimentais até as informativas e de conhecimento. E, ressalte-se, somente a leitura poderá mantê-los vivos.

Sabemos que há leitores para todos os tipos de textos: científicos, de estudo, de higiene mental, de prazer, de literatura, dentre outros. Essa leitura pode ser no intuito de preencher um vazio interior, para se apropriar de um saber momentâneo ou para se utilizar daquele conhecimento adquirido em momento oportuno, ou ainda para satisfazer uma necessidade intelectual, prazerosa, fruitiva sem quaisquer outros compromissos. Mas, e a leitura de um romance clássico, terá algo diferente?

Lembremos que, como definição do termo "clássico", apresentamos o seguinte: "Do latim classicu, diz-se da obra ou autor que, pela originalidade, pureza de língua e forma perfeita, se tornou modelo digno de imitação (HOLANDA, 1999, p. 416).

Perrone-Moisés (2016, p. 65) conceitua as obras clássicas como aquelas cujo juiz é o tempo:

O grande juiz da obra literária é o tempo. Se uma obra continua a suscitar novas leituras, não é porque ela contém valores essenciais, mas porque ela corresponde a indagações humanas de longa duração, concernentes à vida e à morte, ao amor e ao ódio, à paz e à guerra, e porque essas indagações estão nela formuladas numa linguagem cuja eficácia significante é reconhecida por leitores de sucessivas épocas. É esse reconhecimento que faz um clássico [...].

Deste modo, pautamo-nos na concepção de que um clássico seria aquela obra que mesmo com o decorrer do tempo continuaria sendo atual e mais: capaz de suscitar indagações aos seres humanos sobre suas próprias vidas. Essa concepção também vem perpassada por Ítalo Calvino (1993) porque o mesmo reflete que um clássico nem sempre nos ensina necessariamente algo que não sabíamos porque às vezes a pessoa lê e descobre um conhecimento que já intuía em seu íntimo ou parecia já saber, embora não soubesse que o clássico já havia dito, "(ou que de algum modo se liga a ele de maneira particular)". (CALVINO, 1993, p. 12)".

Nesse sentido, uma das premissas em relação à concepção do que seriam livros clássicos se reporta ao reconhecimento devido a uma obra por seu caráter de ensinamento e capacidade de continuar suscitando questionamentos ao longo do tempo.

Por outro lado, o autor ressalta a importância de que ao se ler os clássicos, acenda-se uma centelha em quem os lê: "[...] os clássicos não são lidos por dever ou por respeito, mas só por amor". (CALVINO, 2007, pgs. 12-13). Não obstante e, parafraseando o teórico, ainda assim, evidencia-se a necessidade de a escola fazer com que os alunos conheçam "[...] bem ou mal um certo número de clássicos dentre os quais (ou em relação aos quais) os mesmos poderão ou não reconhecer os seus próprios clássicos" (CALVINO, 1993, p. 12-13).

Pensando nesses pressupostos, propomos a investigação da leitura dos clássicos e o gosto por esse tipo de leitura nas escolas, levantando as seguintes questões: os alunos leem os clássicos? Gostam de ler? Em qual ambiente esse estudante está inserido? Esse fator é importante para o estímulo à leitura? A leitura mudou ao longo do tempo? O suporte virtual tem melhorado ou diminuído a expectativa da leitura de obras clássicas ou de outras leituras? A partir da resposta aos questionários, obtivemos quais respostas em relação à leitura dos clássicos? Essas e outras perguntas são discutidas ao longo desse artigo.

\section{Estudo de caso}

Conforme assinalamos a pesquisa tangenciouse a duas escolas do município de Dourados - MS, denominadas como escola "A" essa pertencente à rede pública de ensino e escola "B" à rede particular. Utilizamos como método de abordagem questionários 
sendo que esses continham questões abertas e fechadas.

O público alvo foram os estudantes do terceiro ano das referidas escolas, cuja faixa etária variava dos 16 aos 19 anos de idade. Em nossos estudos, ora utilizamos 0 método comparativo para compreendermos a situação de cada realidade escolar, ora convergirmos os dados para mapear a conjuntura do problema.

$\mathrm{Na}$ escola $\mathrm{A}$ recolhemos vinte e quatro questionários, na escola $B$ trinta e quatro. $E$, após a aplicação e análise dos mesmos evidenciamos respostas concernentes à leitura ou não dos clássicos brasileiros, a importância atribuída, e outros aspectos que vão esboçados nesse artigo.

Em relação à leitura dos romances clássicos verificamos que, se eles ainda não têm o hábito, a maturidade necessária e não apreciam, por outro lado, atribuem relevância. É o que constatamos ao indagar-lhes da importância dessa leitura. A questão foi a seguinte: Você considera importante a leitura dos clássicos brasileiros? Somando o resultado das duas escolas, cinquenta e seis responderam de forma positiva, sendo que apenas dois assinalaram não, portanto cinquenta e seis alunos consideram importante essa modalidade de leitura.

O questionário apresentava ainda opções sobre o porquê da importância. A maioria assinalou o item onde se diz que essa leitura melhora o nível cultural do leitor (trinta e sete alunos). Com isso percebemos que, mesmo não havendo certo "gosto" ou prazer há valorização por parte desses jovens em relação à leitura dos clássicos.

Para aprofundarmos um pouco mais sobre a relevância atribuída à leitura dos clássicos pelos estudantes ratificamos que, no tocante às respostas, parece haver controvérsia ou ainda, estar subentendida na consciência dos alunos uma vez que, embora alguns afirmaram não gostar a consideram importante.

$\mathrm{Na}$ tentativa de ampliarmos essa reflexão, nos apropriamos de um fragmento do livro: $A$ importância do ato de ler (2000) de Paulo Freire, onde o mesmo explicita que, além da necessidade de se ler um clássico com seriedade, deve haver um aprofundamento na leitura, na busca do âmago do que nela está contido; somente assim viabilizaremos nossa prática enquanto docentes e estudantes:

Parece importante, contudo, para evitar uma compreensão errônea do que estou afirmando, sublinhar que a minha crítica à magicização da palavra não significa, de maneira alguma, uma posição pouco responsável de minha parte com relação à necessidade que temos, educadores e educandos, de ler, sempre seriamente, os clássicos neste ou naquele campo do saber, de nos adentrarmos nos textos, de criar uma disciplina intelectual, sem a qual inviabilizamos a nossa prática enquanto professores e estudantes (FREIRE, 2000, p. 18).

Analisando 0 excerto, os dados e as considerações relatadas pelos alunos sobre o valor dessa leitura e apoiados ainda em Calvino (1993) e Freire (2000), acreditamos que a escola realmente não deve deixar de contemplar na disciplina de Literatura a leitura das obras clássicas brasileiras, pois, com essa metodologia, os alunos terão uma primeira oportunidade de ler e conhecerem os clássicos, não importando se os apreciam ou não, porque ao menos eles passam a conhecerem, saberem sobre o que dizem e o mais importante, "como dizem".

Além disso ao se pensar na leitura dos clássicos e nas relações que os estudantes podem fazer o teórico preconiza que "Os clássicos são aqueles livros que chegam até nós trazendo consigo as marcas das leituras que precederam a nossa e atrás de si os traços que deixaram na cultura ou nas culturas que atravessaram (ou mais simplesmente na linguagem ou nos costumes)" (CALVINO, 1993, p. 11).

Nesse sentido a leitura dos clássicos precederia e apresentaria conotações possíveis que esta leitura pode tomar porque: "Toda releitura de um clássico é uma leitura de descoberta como a primeira. Toda primeira leitura de um clássico é na realidade uma releitura. Um clássico é um livro que nunca terminou de dizer aquilo que tinha para dizer" (CALVINO, 1993, p. 11). 
Vejamos o final da citação de Calvino (1993, p. 11): "[...] um livro que nunca terminou de dizer o que tinha para dizer". Atribuímos relevância ao fragmento com o intuito de respaldar a assertiva de que novas leituras devem ser feitas para descobrirmos algo que antes não se fez presente ao nosso entendimento. É provável que esta circunstância esteja ligada a questões de ordem psicológica, tendo-se como exemplo a maturidade ou ainda, as inferências e leituras anteriores, e também a leitura de mundo. E é dessa forma que estaríamos estabelecendo na vida do leitor um novo momento ou até mesmo projetando um momento futuro: uma possível inédita descoberta por meio dos clássicos brasileiros.

\section{Os clássicos: leitura de valor}

Com relação à importância e ao que pensam sobre os clássicos, os estudantes terceiranistas responderam aos questionamentos por meio de depoimentos sendo esses, um retrato dessa leitura pelos mesmos. Selecionamos, a seguir, algumas dessas declarações, a fim de fazermos algumas considerações sobre o que expuseram.

Para efeitos de comparação, dividimos os alunos em dois grupos e fizemos um recorte das respostas. Primeiro elencamos dos estudantes da escola $A$, sendo respectivamente aqueles que atribuem importância à leitura e em seguida aqueles que não a valorizam. Em seguida, apresentamos os depoimentos dos alunos da escola $B$, seguindo a mesma ordem (preservamos os nomes e o sexo dos alunos):

\subsection{Depoimentos Favoráveis:}

\section{Escola A:}

"O clássico nos leva a compreender as outras épocas, auxilia na hora de escrever e até mesmo falar, faz também termos uma visão diferente do mundo" (T.B. -17 anos)

“(...) pois melhora o nosso grau de interpretação e o nosso conhecimento de uma cultura que é facilmente esquecida" (T.A.H. - 17 anos).
"Sempre aprendemos algo quando lemos essas obras, seja do nosso país, de alguma época marcante, etc." (M. C. L. F. -16 anos).

"Os clássicos trazem conhecimentos de diferentes épocas, fatos cotidianos que interferem na formação educacional" (L. S. - 17 anos).

"É pelos clássicos que se tem a forma concreta da cultura de tempos atrás, ou seja, creio que nossa literatura faz parte da história do Brasil, pois relatam, alguns mais outros menos (sutilmente) os fatos que aconteceram em suas respectivas épocas" (A. M. N. 17 anos).

\section{Escola B:}

"O clássico contribui para o crescimento cultural e intelectual, além do conhecimento histórico" (R. A. O. 17 anos).

"[...] porque nos leva a épocas diferentes, você faz uma viagem na imaginação" (G. G. - 18 anos).

"Porque através destas obras podemos conhecer literalmente momentos sociais, políticos e econômicos da sociedade" (A. S. A. - 17 anos).

"A leitura é muito importante para tudo, conhecimentos, na hora de escrever, falar sem medo e constrangimento; as obras clássicas são muito interessantes não apenas para o vestibular, conhecemos culturas diferentes e outros" (A. R. S. - 18 anos).

"[...] pois mostra um lado mais culto e literário de nossa cultura e muitas vezes trazem boas lições para nossa vida" (M. G. F. - 16 anos).

\subsubsection{Depoimentos Desfavoráveis:}

Após apresentarmos os depoimentos favoráveis, seguem os que não são favoráveis:

"A leitura é pouco importante, pois não tem tanto conteúdo" (J. C. - 17 anos). 
"[...] às vezes se perde muito tempo lendo e quando se chega ao final você percebe que não conseguiu entender" (A. O. R. M. - 17 anos).

"Só serve para a realização da prova do vestibular" (C. M. - 17 anos).

\section{Escola B:}

Encontramos apenas um depoimento entre os alunos da Escola B que acredita ser de pouca importância este tipo de leitura, o aluno assim se expressou:

"Porque você só vai utilizá-la para o vestibular" (D.C. N. -16 anos).

Comecemos nossa análise por três trechos selecionados dos alunos da escola A, são eles: T. B. disse o seguinte: $O$ clássico nos leva a compreender as outras épocas, auxilia na hora de escrever e até mesmo falar, faz também termos uma visão diferente do mundo; M.C.L.: Sempre aprendemos algo quando lemos essas obras, seja do nosso país, de alguma época marcante, etc; e L. S.: Os clássicos trazem conhecimentos de diferentes épocas, fatos cotidianos que interferem na formação educacional.

Depreendemos das respostas que os três alunos assinalaram as obras clássicas enquanto suporte educacional e direcionamento para a educação e formação dos jovens, pois, como disseram, por meio da leitura pode-se aprender muito, desde escrever e falar melhor, até aprender sobre a história do país. Ezequiel Silva (1986, p. 21) aprofunda a questão e amplia um pouco o tema expondo que "a literatura é capaz de criar tensões em nós mesmos e suscitar intuições acerca da vida humana". Isso revela a ascensão intelectual possível mediante o concretismo de uma situação quando adentramos no universo maravilhoso das letras, posto que expressam significados reveladores diante da nossa experiência de vida. Essa assertiva corrobora a concepção de Calvino (1993) em relação às marcas das leituras que nos precederam e os traços deixados por nossa cultura.
Para analisarmos melhor esta questão é importante que observemos a preocupação pedagógica desses alunos. Eles compreendem que com a literatura é possível vermos o mundo de forma diferente. $\mathrm{E}$, mesmo que certo tom poético proceda dos depoimentos, parece-nos que eles estão bem próximos de descobrirem algo mais sobre esse assunto, talvez um leve esboçar de tonalidade crítica necessária, como nos aponta o estudioso Antônio Cândido (1972, p. 805): "A literatura pode formar; mas não segundo a pedagogia oficial. (...) Seja como for, a sua função educativa é muito mais complexa do que pressupõe um ponto de vista estritamente pedagógico".

De modo óbvio o respeitado literato, no excerto acima, examina o assunto sob um ponto de vista mais crítico ao analisar de que maneira a literatura pode aperfeiçoar, educar uma pessoa, mas não a considera como instrumento estritamente pedagógico. Assim, tal como reflete o teórico, se aos alunos falta um pouco de olhar refinado diante das picardias do mundo, consciência e humildade não faltam, pois eles disseram estar sempre aprendendo, mas, aprendendo para quê?

Ora, para a vida, para serem além de verdadeiros cidadãos conhecedores dos seus direitos e deveres e encontro com a própria natureza humana. Isto nos leva a crer que, para esses jovens estudantes, com certeza a literatura exerce uma função humanizadora, capaz de revelar significados e mostrar direções capazes de os conduzir para o bem viver e, por esse motivo, essa busca não pode cessar nunca. Silva (1986, p. 21) reforça nossa hipótese ao afirmar: "No prazer gerado pela complexidade e oscilação dos significados - decorrência natural do movimento de nossa consciência no adentramento do texto literário - vamos conhecendo e compreendendo melhor o mundo e a nós mesmos".

Outro depoimento que julgamos ser interessante é o do aluno G. G. F., da Escola B. Assim ele se expressa sobre ler os clássicos: "[...] porque nos leva a épocas diferentes, você faz uma viagem na imaginação". Poucas palavras e significado intenso. Parece-nos que este se inclina 
mais ante o prazer de se ler uma obra, do que com o que essa possa the ensinar. Porque, mesmo ao afirmar que o texto "nos leva a épocas diferentes", essa mesma assertiva sinaliza um aprendizado, porém destituído do fazer pedagógico contido nas obras apontado pelos outros alunos em seus respectivos depoimentos.

Nesse sentido, o estudante estaria próximo de nos dizer com todas as letras: eu quero viajar na minha imaginação lendo esse livro; eu quero me deleitar com essa preciosa leitura, pois sinto nela o sabor do mais puro mel. A afirmativa do estudante pode ser reforçada ainda mais pelas palavras de Calvino (1993, p. 13) quando expõe sobre isso: "Chama-se de clássico um livro que se configura como equivalente do universo, à semelhança dos antigos talismãs. O "seu" clássico é aquele que não Ihe pode ser indiferente e que serve para definir a você próprio em relação e talvez em contraste com ele".

Em comparação com os alunos os quais veem no clássico uma missão educativa, esse estudante parece ter descoberto que eles não são ou não transmitem somente essa acepção, há neles um teor com poder de se eternizar no âmago do leitor. Ou seja, o estudante citado, ao ler o "seu clássico" consolida a acepção proposta por Calvino (1993) porque para ele, a leitura dos clássicos fez e faz uma diferença admirável em sua vida de leitor.

Por outro lado, os depoimentos dos estudantes C. M. e D. C. N., cujas respostas não atribuem importância à leitura dos clássicos porque, "só serve mesmo para se fazer o vestibular". A partir dessa afirmação, podemos considerar alguns aspectos que os tenham impelido a essa opinião: um deles concerne ao próprio sistema educacional brasileiro, porquanto a preocupação desses jovens, ao ingressarem no ensino médio, reduz o ato de leitura dos clássicos à aprovação no vestibular. Outro fator, tangencia-se ao capital cultural (BOURDIEU, 1998) dos alunos. E, por último, podemos dizer que esses alunos ainda não "descobriram" essa leitura proposta por Calvino (1993), embora nada os impeçam de virem a fazê-lo.
A partir da releitura dos questionários cuja leitura circunscreve-se ao ato de passar no vestibular ou obter boa pontuação no ENEM, evidenciamos que a nossa hipótese de que eles ainda não "descobriram" essa leitura como quer Calvino (1993) se confirma, pois, numa outra questão que os indaga sobre o porquê de eles terem lido os clássicos, ambos responderam de forma franca que o objetivo da leitura era tão somente para o vestibular ou porque o professor assim o exigiu.

Do mesmo modo, a proposição alusiva ao capital cultural também parece se confirmar porque, no questionário, o aluno C.M., embora tenha respondido que seu pai não tem o hábito de ler e sua mãe leia apenas o jornal, ao indagarmos se em sua casa havia romances clássicos ele respondeu que sim, porém admitiu não ter o hábito de lê-los. Já o estudante D. C. N. afirmou que os pais leem somente revistas e, em relação à presença dos clássicos em casa admitiu a existência, embora ratifique não os ler com frequência.

Assim, infere-se das respostas que, dos dois estudantes, o representado pela sigla D. C. N. da escola B aparenta pertencer a um ambiente mais propício à leitura do que o aluno C. M., embora ambos não convivam em um meio onde se pode afirmar a existência de elementos favoráveis para serem leitores assíduos e valorizar de fato a leitura tal como preconizam os estudiosos dessa área.

\section{Tipologia de leitura}

Com o fito de analisarmos as tipologias textuais lidas por esses estudantes auferimos as seguintes respostas a esse item: romances, a bíblia; gibis, revistas informativas, livros de teoria e jornal, sendo as três opções mais votadas as revistas informativas, seguidas dos jornais e a bíblia.

Nesse sentido, ao se pensar a sociedade contemporânea e valorização do ser humano apenas pela sua capacidade de produzir, era mesmo de se esperar que esses jovens apontassem em primeiro lugar para a leitura de revistas informativas. Isso porque credita-se a esse tipo de leitura, a faculdade de colocar esse leitor numa situação social 
privilegiada em razão da sua função precípua de atualização em relação aos acontecimentos.

Sobre esse assunto, Chartier e Hébrard (1995, p. 589) expõem claramente como a modernidade prescreve o que atualmente se estabelece em termos de leitura: "a nova norma preceitua que é preciso ler tanto para se informar quanto para se formar, mediante 0 recurso simultâneo às aprendizagens eficazes, bem trabalhadas didaticamente, e à leitura de prazer". Isso porque, para esses autores, a leitura deve "servir tanto para se instruir como para se distrair, ao mesmo tempo muito e bem, depressa e devagar". (CHARTIER e HÉBRARD, 1995, p. 589)

Assim, corroborando 0 que dissemos anteriormente sobre o papel da escola em relação ao estudo da literatura e consequentemente da leitura dos romances clássicos, os autores acrescentam: "É na escola que emerge com maior clareza este modelo contemporâneo do ler, visto que ela não pode abandonar a leitura de formação (que fundamenta em suas práticas) nem recusar a leitura de informação (que a avaliza em seus discursos)" (CHARTIER e HÉBRARD, 1995, p. 589).

Não obstante à citação, parece-nos que a escolha da revista de informação pelos alunos levou em consideração tão somente a formação para o enfrentamento da vida em sociedade. É provável os estudantes terem assinalado esse item por acreditarem como mais importante a leitura informativa que a do livro, ou ainda, pelo fato dessa leitura ser "cobrada" periodicamente. Assim, creditam esse sucesso à apropriação de informações, mas esquecem ou até mesmo não são bem instruídos de que uma boa formação advém da junção das leituras para um desenvolvimento mais aprimorado.

Acreditamos ainda que esta posição pragmática advenha da concorrência sentida e imposta aos estudantes, fato esse confirmado ao se pensar na sociedade e seus motivos excludentes claramente instituídos, tendo-se como exemplo a disputa por uma vaga em uma boa universidade ou no mercado de trabalho, acontecimentos cada dia mais difíceis de serem alcançados.
Portanto, ficar fora desse processo não é nem um pouco aconselhável e talvez, por extensão, os alunos pensem que ler os clássicos não Ihes trará resultados expressivos em suas vidas por acreditarem ser mais importante estarem bem informados, como se apenas essa leitura contribuísse para o sucesso na sociedade atual.

Contudo, ler pouco ou ainda, apenas uma tipologia de leitura, eleva o risco vertiginoso da estagnação. Para Perrone-Moisés (2016, p. 78): "Se a experiência da leitura é pouca, a tendência do leitor é gostar daquilo que já conhece, e quanto menos conhecer, menos terá disposição de enfrentar o trabalho que representa a leitura de um texto mais complexo".

Assim, ao se priorizar a leitura de cunho informativo tem-se como consequência um aprendizado estanque e essa escolha parcial afeta os estudantes sobremaneira porque os priva da qualidade e profundidade necessária, tanto para a formação do leitor bem como para o desenvolvimento crítico como cidadão e consequente apropriação da cultura universal, cuja formação exige uma leitura mais aprofundada. Nesse sentido, a escritora Ana Maria Machado (1999, p. 110), reflete:

[...] por outro lado, viveu-se também uma grande perda - a da profundidade, da verticalidade. E com isso, desapareceu também a busca de uma qualidade até então muito valorizada em todas as sociedades humanas e tradicionalmente associada à experiência e à leitura. Ou seja, deixou-se de ter como ideal a sabedoria. Fica cada vez mais fácil informar-se, ter conhecimento. Mas em meio a tamanha explosão de dados, muita coisa escapa, fica também cada vez mais difícil compreender.

Da citação, é importante destacar a afirmativa da autora sobre cada dia ser mais difícil "compreender". De acordo com o dicionário essa palavra significa "alcançar, abraçar" (HOUIAISS, 2003, p. 151), mas, como atingir esse objetivo em meio a uma avalanche de informações vertidas sobre o leitor as quais nem sempre atestam sua validade? Inclusive, é desse emaranhado de informações que decorre o problema da apreensão pois esta, passa a ser superficial, momentânea, fragmentada de modo 
que não assegura o conhecimento adequado o qual eleva o nosso espírito e nos torna de fato mais sábios.

Por outro lado, na prática escolar, cumpre auscultar a afirmação de Chartier e Hébrard. Para os mesmos, o trabalho de leitura deve contemplar a de formação, de informação e ainda acrescem a esse rol, a de prazer. Acreditamos que a partir dessa acepção e levando-se em consideração o que expusemos, podemos considerar a leitura dos clássicos como uma leitura de formação, leitura esta que, apesar de sofrer ameaças de toda ordem, ainda se faz presente, conforme observamos no ensino médio.

A essas ameaças as quais nos referimos em desfavor da leitura, acredita-se que as mais contundentes se relacionam ao uso da televisão e da internet, isto é, há a possibilidade de os leitores hodiernos trocarem o livro pelas telas. $\mathrm{Na}$ era da imagem, da velocidade, é o imediatismo a roubar a cena. Isso porque, diferente da leitura não há a necessidade de se refletir profundamente, basta apenas assimilar suas intenções sem muito esforço. E então pergunta-se: teremos futuramente uma nova sociedade composta unicamente de leitores de imagens?

Não sabemos. Mais é inegável que, para muitos estudantes é bem mais cômodo assistir a um filme do que ler um livro, e há, é claro, os filmes sobre os livros, até sobre os clássicos brasileiros como é o caso de Iracema de José de Alencar, Inocência de Visconde de Taunay, $A$ Moreninha de Joaquim Manuel de Macedo e tantos outros. Por isso é comum ouvir os alunos do ensino médio e até estudantes de Letras perguntarem se "tal clássico já tem em filme". Então, o que nos aguarda adiante? Será a tecnologia capaz de encontrar um instrumento que substitua o livro, as letras? Será isso possível? Para Ana Maria Machado (1999, p. 8) não, conforme afirma:

Não creio, porém, que as novas tecnologias possam vir a substituir a leitura ou o livro de literatura - romance, conto, ensaio, poesia. Eles têm mudado, mas continuam. Não é a primeira vez na história que se vive uma mudança desse vulto, pelo advento de novas tecnologias. Na Grécia, muitos séculos depois de Homero, no tempo de Sócrates, a cultura oral dominante foi sobrepujada pela tecnologia da escrita. E no renascimento europeu, quando Gutemberg inventou a imprensa com tipos móveis, houve nova revolução.

Portanto, uma resposta à indagação em relação à imagem sobrepujar a leitura, é negativa pois, conforme pontua Machado (1999), o livro deverá ter vida longa e se fará presente nas gerações vindouras, pois, mesmo diante das transformações de toda ordem, a leitura deverá ter o seu lugar assegurado.

Por outro lado, ao nos pautarmos no fato de que o livro e a leitura representam conhecimento, Tânia Pellegrini aponta que a forte presença da imagem está, atualmente, assinalando um novo caminho para a construção do próprio conhecimento entre as pessoas. Para a autora: “(...) com a mídia, está gradativamente se modificando a natureza do conhecimento, que passa a ser traduzido em quantidade de informação transmitida, na grande maioria por meio de imagens, a ponto de as coisas só existirem na mente depois de produzidas e/ou veiculadas por esses estímulos imagéticos" (PELLEGRINI, 1995, p. 78).

Temos então duas opiniões divergentes em relação ao livro e consequentemente para a leitura das letras, pois, enquanto Machado (1999) acredita na eternização do ato de ler tradicional abordado nesse artigo, Pellegrini (1995) é categórica ao afirmar que, devido ao avanço tecnológico, é provável que teremos no futuro uma sociedade de leitores de imagens, conforme ratifica: "Pode-se afirmar, então, que com o fortalecimento da indústria cultural e basicamente da TV, cada vez mais a imagem eletrônica insinua-se em todas as dimensões da vida quotidiana, ubíqua, surgindo como realidade autoreferencial, remetendo a si mesma, numa infinita cadeia de significantes" (PELLEGRINI, 1995, p. 78).

Contudo, após essas citações contraditórias surge a pergunta: mesmo com a presença da televisão, do computador, da imagem, das tecnologias, de maneira geral, lê-se menos ou mais? E no que tange aos clássicos, lia-se mais em tempos 
longínquos ou atualmente? Nesse sentido, também há opiniões divergentes.

O escritor Pedro Bandeira, autor de diversos livros infanto-juvenis, tem uma opinião que pode gerar certa polêmica no meio acadêmico. Numa entrevista bem-humorada ao Jornal "Proleitura" ele tanto falou da situação atual quanto discorreu sobre sua geração defendendo-a como leitora dos clássicos. A pergunta foi a seguinte: "Boa parte da crítica acusa a expansão da literatura infanto-juvenil no Brasil e sua intensa circulação nas escolas como responsáveis pelo fato de poucos jovens hoje conhecerem os clássicos de nossa literatura. Como o senhor vê essa questão?" (BANDEIRA, 1998, p. 01)

O escritor, munido de bom humor e convicção, respondeu:

Eram lidos menos do que hoje. Que história é essa de que antigamente todas crianças liam os clássicos? Elas nunca leram os clássicos. Nunca! Jamais! A minha geração toda não lia. Meu grupo de amigos lia, porque nós éramos meio malucos lá em Santos e gostávamos de ler. Mas éramos meia dúzia de pessoas aliás, a Marisa Lajolo, que é professora de Teoria da Literatura na UNICAMP, era da nossa turma.

$\mathrm{Na}$ primeira parte do entrecho, o escritor avaliou que poucos de sua geração liam os clássicos: "éramos apenas meia dúzia". Acreditamos, porém, que essa meia dúzia fez e ainda faz muita diferença no país tanto pelo conhecimento desse escritor, quanto pelo da professora Marisa Lajolo, a qual ele cita e comenta ser de sua turma. Isto também corrobora nossa premissa de que a leitura dos clássicos deve seguramente fazer diferença na vida intelectual das pessoas.

Deste modo, esses profissionais podem ser citados enquanto exemplo dessa assertiva, pois é inegável serem pessoas de ilibado respeito em razão do trabalho intelectual que desenvolvem para a literatura nacional. Com isso, constatamos mais uma vez que, mesmo os alunos não gostando de ler estas obras, as mesmas representam muita importância para a sua formação intelectual.

$\mathrm{Na}$ sequência, Bandeira (1998, p. 01) comentou a respeito da influência da televisão e da internet sobre a leitura: "Todo mundo diz que as crianças não lêem hoje porque há a televisão e a internet, que as afastam do livro. Quer dizer que antes de inventar a televisão no Brasil todo mundo lia? Lia nada! A produção de livros no Brasil era pequena, poucas pessoas liam. Hoje se lê muito mais, o número de livros que se consome no Brasil é muito maior do que jamais foi em toda a História".

Depois dessas considerações sobre a influência das famosas "telinhas" sobre a leitura, o escritor tece uma crítica à forma como um aluno é submetido abruptamente à leitura de um clássico brasileiro. Ele diz que "há um momento em que obrigam um jovem que nunca leu nada durante toda sua vida a ler Machado... Se ele não tem o hábito de leitura, como é que vai gostar de ler Machado"? (1998, p. 02)

Essa afirmação nos reporta a considerações acerca do "aquecimento" dos alunos, à importante função da escola na didática de se abordar a leitura dos clássicos. Os estudantes devem ser preparados para isso, é preciso antes construir condições para se alcançar bons resultados e essas se estabelecem desde o hábito da leitura em geral, isto é, de qualquer texto que poderá ser de literatura infanto-juvenil, contos, crônicas e outros, até a explicação por parte do professor sobre o que é um clássico. De tal modo, o professor obterá melhores resultados com esses jovens leitores.

Ainda para reforçar o que Bandeira afirma em relação às tecnologias não constituírem obstáculo para a leitura, Ana Maria Machado apregoa o seguinte: "Fala-se muito em ameaças ao livro e à leitura. Diz-se que as crianças estão lendo menos ou que os livros estão condenados a desaparecer porque são caros demais ou não conseguem atrair leitores diante dos CD-ROMs e computadores (aí ninguém se lembra do preço de CD-ROM e computador)" (MACHADO, 1999, p. 95).

Ao continuar o mesmo raciocínio, ainda acrescenta:

Nenhuma reflexão que tente entender a palavra escrita hoje em dia pode esquecer dois fatos inquestionáveis e fundamentais. 0 
primeiro é que centenas de milhões de seres humanos estão agora, pela primeira vez, entrando no mundo da leitura e da escrita. $O$ segundo é que, ao contrário da televisão e do vídeo (tecnologias visuais perfeitamente ao alcance de qualquer analfabeto, extensão da velha cultura oral), agora com os computadores e meios interativos há uma reabilitação da importância da palavra escrita. As novas tecnologias exigem alfabetização e capacidade de leitura. (MACHADO, 1999, p. 112).

O que nos resta saber é se, atrelado a esses índices houve aumento da leitura de obras clássicas. Para o escritor Pedro Bandeira, como já vimos, sim, porém há quem diga o contrário. Perrone-Moisés (1998, p. 206) contrapõe o escritor ao afirmar: "A alta cultura, a criação desinteressada, ou interessada em ampliar o conhecimento e a experiência humanos, em aguçar os meios de expressão, em despertar o senso crítico, em imaginar outra realidade, tudo está ameaçado de extinção".

Nesse sentido, a leitura dos clássicos estaria ameaçada por força de algo que se institui a cada dia na sociedade ocidental. A própria autora pondera que "os valores estético-literários são diária e progressivamente vencidos por uma cultura de massa embrutecedora, ou transformados em mercadoria de grife na indústria cultural” (PERRONE-MOISÉS, 1998, p. 206). Assim, de acordo com a estudiosa, a derrota dos clássicos é fato que povoa o momento com tamanha força, mas também as sequela.

Reforça ainda o prejuízo resultante dado o distanciamento do manancial de complexidade, reflexão, realização e aprofundamento intelectual sobre os que estão dispostos a conhecê-los. Não obstante os obstáculos, pontua a importância de se ler os clássicos ou mesmo relê-los porque "[...] a obra literária é um texto que faz pensar e sentir de modo mais profundo e duradouro e que, por isso, tem de ser lido mais vagarosamente, e mesmo relido. (PERRONE-MOISÉS, 2016, p. 37).

Assim ratifique-se o cuidado em observar que a leitura dos clássicos exige por parte do leitor a reflexão necessária e aprofundada e, suscita, até mesmo, sua releitura. Porém, nada obsta que o professor possa se utilizar como prática das próprias tecnologias no intuito de apresentar os clássicos aos alunos. Pode por exemplo, começar pelos contos e crônicas até se chegar aos renomados clássicos brasileiros. Nesse sentido, até mesmo o celular seria de grande valia em sala de aula pois, permitiria que os alunos baixassem os livros solicitados, assim teriam acesso não tão somente durante as aulas, mas também em casa tendo a oportunidade de continuarem a leitura.

Essa intenção viria de encontro ao afirmado por Pedro Bandeira quanto à quantificação da leitura em outras épocas. O mesmo enfatizou ser pouca ou quase nenhuma, abordando como uma das razões a baixa tiragem de livros. Para se ter uma ideia em relação a esse fato, na mesma entrevista, o escritor mencionou que o romance Vidas Secas, uma das obras-primas da literatura nacional, teve uma primeira tiragem de 3.000 exemplares no ano de 1938, além do alto preço. Ressaltou ainda que anos se passaram até 0 esgotamento dessas obras. Também mencionou em relação à Machado de Assis a tiragem de apenas 300 exemplares no século passado, ao passo que hoje as tiragens são muito maiores.

Portanto, é realmente importante se questionar a afirmação de que hoje o estudante não lê e mais, não lê literatura clássica ainda mais porque isso não quer dizer que todos os estudantes de todas as realidades sociais leiam os clássicos ou tenham acesso a ela, ou, ainda que a tenham, não possa ser via suportes diferentes dos livros, seja pela tela do computador, ou do próprio celular.

Não obstante, concordamos com Calvino (1993) de que os mesmos tenham contato com os clássicos ao menos na escola. Assim, ainda que alguns estudantes leiam apenas pela pontuação no ENEM ou somente por exigência do(a) professor(a) esse ato vai de encontro ao sugerido por Calvino (1993) quando discorre que a leitura dos clássicos, embora deva ser objeto de escolha dos estudantes por amor ou prazer constitui obrigação da escola "[...] dar-Ihes instrumentos para efetuar uma opção" (CALVINO, 1993, p. 13).

Deste modo, algumas das respostas do questionário tais como: "Só serve para a realização da prova do vestibular" (C. M. - 17 anos), explicitam 
que, apesar de alguns estudantes afirmarem ler tão somente em decorrência do ENEM ou visando o vestibular ou até mesmo atendendo a exigência do(a) professor(a), constitui, conforme Calvino (1993) condição melhor do que se não tivessem nenhum contato com obras clássicas.

Ademais, é necessário frisar que da leitura geral dos questionários observamos que alguns leem somente o resumo dessas obras e outros sequer têm o hábito da leitura. Contudo, com o intuito de ampliarmos a discussão sobre este assunto, devemos considerar vários fatores os quais não podemos deixar de ponderar. Um deles refere-se à massificação da educação.

Hoje, quase todos vão à escola e têm contato com livros, ao passo que antes, ou, para sermos mais precisos, nas décadas de 30, 40 e 50, 60, 70 do século $X X$, possivelmente o período mencionado por Pedro Bandeira, o acesso à escola era bem menor porque apenas uma pequena elite enriquecida a frequentava. Isto se devia em razão da escassez de instituições de ensino. Na realidade, não havia muitas escolas, muito menos para aqueles sem condições socioeconômicas a favorecerem o acesso.

Cumpre então em vista do que se expôs, fazermos uma indagação: como se pode afirmar que antigamente lia-se muito se tínhamos poucas escolas para formar leitores? Nesse sentido, parece-nos claro que, no período citado, somente uma pequena "nata" da sociedade brasileira tinha acesso à escola. E são esses poucos, provavelmente abastados que liam possivelmente os clássicos da literatura nacional e estrangeira, uma vez que, já nessa época, este tipo de leitura podia apontar diferenças sócio-culturais entre as famílias.

Hoje, com a expansão do oferecimento adequado à demanda escolar, a conclusão é que, apesar dos estudantes priorizarem outros tipos de leitura, ou ainda, apesar dos mesmos sentirem-se mais próximos das leituras oportunizadas pelas mídias, ainda assim, o número de leitores aumentou em relação ao passado, embora talvez não com a profundidade necessária para a boa formação do leitor, ou para o desenvolvimento crítico que a leitura dos clássicos propicia.

Assim, retomando nossos apontamentos e análises aqui demonstradas, é possível dizer que, apesar de todos os contratempos, da presença da tecnologia e das "telinhas", os estudantes do ensino médio, na sua maioria quando leem os clássicos brasileiros, apreciam a leitura e atribuem grande valor a ela, tanto do ponto de vista histórico-social, quanto pedagógico. Assinalamos ainda a necessidade de reavaliação dos próprios docentes em se utilizarem inclusive dessas tecnologias para esse contato com os clássicos e acenderem essa primeira centelha nos alunos.

Portanto, é nesse sentido que podemos demarcar a grande responsabilidade da apresentação dos clássicos aos alunos pela escola, encargo esse que se estende ao professor no desenvolvimento de um trabalho sistematizado desde ao apresentar o que é um clássico literário ao estudante, ou ainda, ao balizar sua importância até a evolução do gosto por essa leitura precípua aos mesmos, seja como instrumento de formação de leitores, seja para o desenvolvimento crítico e a apropriação cultural que desse ato emana. Ou, como um de nossos estudantes afirma: "[...] pois mostra um lado mais culto e literário de nossa cultura e muitas vezes trazem boas lições para nossa vida" (M. G. F. - 16 anos).

\section{Referências}

BANDEIRA, Pedro. Nascido para narrar: uma entrevista com o escritor Pedro Bandeira. Tablóide Proleitura, no 22, p. 1-3, out. 1998.

BOURDIEU, Pierre. Os três estados do capital cultural. In: NOGUEIRA, Maria Alice; CATANI, Afrânio (Org.). Escritos de educação. 2 ed. Petrópolis: Vozes, 1998.

CALVINO, Ítalo. Por que ler os clássicos. 2 ed. Trad. de Nilson Moulin. São Paulo: Companhia das Letras, 1993.

CÂNDIDO, Antônio. A literatura e a formação do homem. Revista Ciência e Cultura, São Paulo: USP. V. 24, n. 09, p. 803-809, 1972. 
CHARTIER, Anne-Marie; HÉBRARD, Jean. Discursos sobre a leitura - 1880-1980 -. 5 ed. Trad. de Osvaldo Biato e Sérgio Bath. São Paulo: Ática, 1995.

FREIRE, Paulo. A importância do ato de ler. 39 ed. São Paulo: Cortez, 2000.

FERREIRA, Aurélio Buarque de Holanda. Novo Dicionário Aurélio século XXI: o dicionário da Língua Portuguesa. 3 ed. Totalmente revista e ampliada. Rio de Janeiro: Nova Fronteira.

HOUAISS, Antônio, VILLAR, Mauro; FRANCO, Francisco Manoel de Mello. Dicionário Houaiss de Sinônimos e Antônimos. Rio de Janeiro: Editora Objetiva, 2003.

MACHADO, Ana Maria. Contracorrente: Conversas sobre leitura e política. São Paulo: Ática, 1999.

PELLEGRINI, Tânia. Aspectos da produção cultural brasileira contemporânea. Crítica Marxista, São Paulo, Brasiliense, v.1, nf.2, 1995, p.69-91. Disponível em: http://www.ifch.unicamp.br/criticamarxista/arquivos biblioteca/artigo266Artigo5.pdf Acesso em: 20/01/17.

PERRONE-MOISÉS, Leyla. Altas Literaturas. São Paulo: Companhia das Letras, 1998.

- Mutações da Literatura no século XXI. São Paulo: Companhia das Letras, 2016.

SILVA, Ezequiel Theodoro da. Leitura na escola e na Biblioteca. 2 ed. São Paulo: Papirus, 1986.

\section{COMO CITAR ESSE ARTIGO}

PERON, Eliza da Silva Martins; SAMPAIO, Emílio Davi. LITERATURA: UM ESTUDO DE CASO DA LEITURA DOS CLÁSSICOS BRASILEIROS NO ENSINO MÉDIO. Signo, Santa Cruz do Sul, v. 43, n. 78, nov. 2018. ISSN 1982-2014. Disponível em: <https://online.unisc.br/seer/index.php/signo/article/view/11672>. Acesso em: doi: https://doi.org/10.17058/signo.v43i78.11672. 